\title{
Removal of cadmium(II) from aqueous solutions by steam- activated sulphurised carbon prepared from sugar-cane bagasse pith: Kinetics and equilibrium studies
}

\author{
K Anoop Krishnan and TS Anirudhan* \\ Department of Chemistry, University of Kerala, Kariavattom, Trivandrum-695 581, Kerala, India
}

\begin{abstract}
Removal of cadmium(II) from aqueous solutions was studied using steam activated sulphurised carbon (SA-S-C) prepared from bagasse pith (a sugar-cane industry waste). Batch adsorption experiments were performed as a function of solute concentration, contact time, adsorbent dose, $\mathrm{pH}$, temperature and ionic strength. The maximum removal took place in the $\mathrm{pH}$ range of 5.0 to 9.0. The maximum adsorption of $98.8 \%(24.70 \mathrm{mg} / \mathrm{g})$ took place by SA-S-C with $8.9 \%$ sulphur content at $\mathrm{pH} 6.0$ from an initial Cd(II) concentration of $50 \mathrm{mg} / \mathrm{dm}^{3}$. The sorption process follows pseudo-second-order kinetics. Kinetic parameters as a function of initial concentration and temperature were determined to predict the adsorption behaviour of $\mathrm{Cd}(\mathrm{II})$ onto SA-S-C. Decrease in ionic strength of the solution was found to improve the adsorption capacity of the adsorbent. The equilibrium data could be best fitted by the Langmuir adsorption isotherm equation over the entire concentration range ( 50 to $\left.1000 \mathrm{mg} / \mathrm{dm}^{3}\right)$. The effectiveness of the SA-S-C for Cd(II) removal was examined and compared with other adsorbents reported in the literature. At solution $\mathrm{pH}$ of 6.0, the maximum adsorption capacity of SA-S-C calculated by the Langmuir isotherm is $149.93 \mathrm{mg} / \mathrm{g}$ at $30^{\circ} \mathrm{C}$. Acid regeneration was tried for several cycles with a view to recover the sorbed metal ions and also to restore the sorbent to its original state.
\end{abstract}

Keywords: Adsorption dynamics, Langmuir equation, Cd(II) removal, Sulphurised carbon, Desorption

\section{Introduction}

Cadmium $(\mathrm{Cd})$, which is widely used and extremely toxic in relatively low dosages, is one of the principle heavy metals responsible for causing kidney damage, renal disorder, high blood pressure, bone fraction and destruction of red blood cells (Drash, 1993). Because of the toxicity and bioaccumulation, $\mathrm{Cd}(\mathrm{II})$ is considered as a priority pollutant by the U S Environmental Protection Agency. The permissible limit for Cd(II) as described by WHO is $0.01 \mathrm{mg} / \mathrm{dm}^{3}$. The main anthropogenic pathway through which $\mathrm{Cd}$ (II) enters the water bodies is via wastes from industrial processes such as electroplating, plastic manufacturing, metallurgical processes and industries of pigments and $\mathrm{Cd} / \mathrm{Ni}$ batteries (Cheremisinoff, 1995). Adsorption of heavy metal ions onto activated carbon has been applied widely as a unit operation in the treatment of industrial wastewater. The use of commercial activated carbon is not suitable for developing countries because of its high cost. Therefore, there is a need to produce activated carbon from cheaper and readily available materials, which can be used economically on a large scale. Activated carbons prepared from rice husk, groundnut husk, fertiliser waste slurry, peanut hull, jute stick, Moringa oleifera seed husk, coconut husk and sawdust (Manju and Anirudhan, 1997; Raji et al., 1997; Warhurst et al., 1997) have been used for wastewater treatment and the potential of their ultimate usage may be determined by their adsorption capacity, regeneration characteristics and physical properties of the subsequent product.

\footnotetext{
* To whom all correspondence should be addressed.

蛊+2731260 3375; fax: +27312601118; e-mail: tsani@rediffmail.com Received 22 April 2002; accepted in revised form 25 January 2003.
}

In recent years considerable attention has been devoted to develop surface modified carbons from locally available materials for the treatment of heavy metal-bearing wastes. Removal of heavy metals from wastewater by adsorption on copper and lanthanum impregnated activated carbons from sawdust and coconut husk has been reported (Manju et al., 1998; Raji and Anirudhan, 1999). Recent studies speculated that the reaction between heavy metal ions and sulphur groups present in the adsorbent materials accounted for high adsorption efficiency. In this direction, GomezSerrano et al. (1998) reported the ability of commercial activated carbon loaded with sulphur groups for the removal of $\mathrm{Hg}(\mathrm{II}), \mathrm{Pb}(\mathrm{II})$ and Cd(II). Sreedhar et al. (1999) studied the sorption of $\mathrm{Hg}(\mathrm{II})$ by polysulphide-treated coconut husk. Bagasse pith is a sugar industry waste by-product, which is available in large quantities at no cost and can form a good basis for the development of adsorbent materials. Only a limited number of studies, however, have so far been focused on the use of bagasse pith for the removal of heavy metal ions from wastewater (Gupta et al., 1998; Peternele et al., 1999). Earlier workers have successfully used a single-step steam pyrolysis activation to make high-quality carbon from a variety of materials (Warhurst et al., 1997). The purpose of this work is to study the possibility of the utilisation of single-step steam pyrolysis in the presence of $\mathrm{H}_{2} \mathrm{~S}$ and $\mathrm{SO}_{2}$ for the production of sulphurised carbon for the reduction of cadmium concentration in the solution, since this material has not been considered previously for this purpose. This study examines the effects of the initial concentration of Cd(II), adsorbent dose, initial $\mathrm{pH}$, contact time, temperature, etc. in metal adsorption with bagasse pith-based sulphurised activated carbon prepared by single-step steam pyrolysis in the presence of $\mathrm{H}_{2} \mathrm{~S}$ and $\mathrm{SO}_{2}$ and the results are presented in this paper. Desorption and regeneration studies have also been carried out. 


\begin{tabular}{|c|c|c|c|c|c|}
\hline \multicolumn{6}{|c|}{$\begin{array}{l}\text { TABLE } 1 \\
\text { Surface and physical properties of the investigated activated carbons }\end{array}$} \\
\hline \multirow[t]{2}{*}{ No. } & \multirow[t]{2}{*}{ Parameters } & \multicolumn{4}{|c|}{ Value } \\
\hline & & SA-C & SA-S(2.3)-C & SA-S(6.8)-C & SA-S(8.9)-C \\
\hline 1 & Surface area $\left(\mathrm{m}^{2} / \mathrm{g}\right)$ & 536.5 & 523.6 & 509.5 & 500.5 \\
\hline 2 & Cation exchange capacity (meq/g) & 3.96 & 4.12 & 4.63 & 5.02 \\
\hline 3 & $\rho_{\text {nitrobenzene }}\left(\mathrm{g} / \mathrm{cm}^{3}\right)$ & 0.87 & 0.80 & 0.91 & 1.22 \\
\hline 4 & $\mathrm{pH}_{\mathrm{zpc}}$ & 5.8 & 5.5 & 4.7 & 4.3 \\
\hline 5 & $\mathrm{~V}_{1}\left(\mathrm{~cm}^{2 p c} / \mathrm{g}\right)$ & 0.13 & 0.10 & 0.06 & - \\
\hline 6 & $\mathrm{~V}_{2}\left(\mathrm{~cm}^{3} / \mathrm{g}\right)$ & 0.20 & 0.23 & 0.28 & 0.33 \\
\hline 7 & $\mathrm{~V}_{3}^{2}\left(\mathrm{~cm}^{3} / \mathrm{g}\right)$ & 0.19 & 0.17 & 0.14 & 0.10 \\
\hline 8 & $\mathrm{~V}_{\mathrm{T}}^{3}\left(\mathrm{~cm}^{3} / \mathrm{g}\right)$ & 0.52 & 0.50 & 0.48 & 0.43 \\
\hline 9 & Sulphur content $(\%)$ & - & 2.3 & 6.8 & 8.9 \\
\hline 10 & Total acidic groups (meq/g) & 2.0 & 2.6 & 2.8 & 2.9 \\
\hline 11 & Carboxyl groups & 0.61 & 0.67 & 0.70 & 0.77 \\
\hline 12 & Phenolic acidic groups & 0.42 & 0.35 & 0.33 & 0.30 \\
\hline 13 & Particle size (mesh size) & $-80+230$ & $-80+230$ & $-80+230$ & $-80+230$ \\
\hline
\end{tabular}

\section{Materials and methods}

\section{Adsorbent preparation}

The bagasse pith collected from a sugar industry, the Co-operative Sugars Ltd., Palakkad, Kerala, India was washed several times with distilled water and left to dry. The carbonisation of the bagasse pith was performed in a Matri-made muffle furnace (India) at $200^{\circ} \mathrm{C}$ for $2 \mathrm{~h}$ (C-200). Steam activation (SA) of the carbon (C-200) was carried out using the method described by the earlier workers (Warhurst et al., 1997). About $50 \mathrm{~g}$ of the carbon was placed in a purpose-made graphite tube and positioned at the centre of the furnace. Steam produced by a steam generator, entered the graphite tube at a rate of approximately $5 \mathrm{~cm}^{3} / \mathrm{min}$. The sample was heated at a rate of $10^{\circ} \mathrm{C} / \mathrm{min}$ to $400^{\circ} \mathrm{C}$ and held at this temperature for $1 \mathrm{~h}$. After allowing the furnace to cool to room temperature, the product steam- activated carbon (SA-C) was removed and washed with $1 \mathrm{M}$ $\mathrm{HCl}$ and distilled water. The material was dried at $100^{\circ} \mathrm{C}$ and sieved to $-80+230$ mesh size.

Steam-activated sulphurised carbon (SA-S-C) was prepared by steam activation of $\mathrm{C}-200$ at $400^{\circ} \mathrm{C}$ in the presence of $\mathrm{H}_{2} \mathrm{~S}$ and $\mathrm{SO}_{2}$ for $2 \mathrm{~h}$. About $50 \mathrm{~g}$ of C-200 was placed in a graphite tube and flushed with a flow of steam $\left(5 \mathrm{~cm}^{3} / \mathrm{min}\right)$ in the presence first of a stream of $\mathrm{SO}_{2}\left(10 \mathrm{~cm}^{3} / \mathrm{min}\right)$ for $90 \mathrm{~min}$ and then of $\mathrm{H}_{2} \mathrm{~S}\left(15 \mathrm{~cm}^{3} /\right.$ $\mathrm{min}$ ) for $30 \mathrm{~min}$ from a gas generator at a heating rate of $10^{\circ} \mathrm{C} / \mathrm{min}$ from 30 to $400^{\circ} \mathrm{C}$. Yield of the finished product was $43.0 \%$ of the original material. The product was washed with distilled water and dried at $100^{\circ} \mathrm{C}$. The dried material was then ground and sieved to separate particles of $-80+230$ mesh size.

\section{Adsorbent characterisation}

The amount of sulphur attached to the carbon sample was determined by using the Eschka method (Rump and Krist, 1992). The method deals with the transformation into $\mathrm{BaSO}_{4}$ of the sulphur present in adsorbents by treatment with the Eschka mixture $\left(\mathrm{Na}_{2} \mathrm{CO}_{3}\right.$ and $\mathrm{MgO}$ ) at $800^{\circ} \mathrm{C}$ and then successively with $\mathrm{Br}_{2}$ and $\mathrm{BaCl}_{2}$ solutions. The infrared spectra of the activated carbons were recorded on a Perkin-Elmer FTIR spectrophotometer (Model IR180) through a wavelength range of 400 to $4000 \mathrm{~cm}^{-1}$. The surface area of the adsorbents was determined using the $\mathrm{N}_{2}$ gas adsorption method with a Quantasorb Surface Area Analyser, USA (Model Q S-7). The porosity and density ( $\left.\rho_{\text {nitrobenzene }}\right)$ of the adsorbent were determined by using the Micrometrics Mercury Porosimeter (Model 9310) and pycnometric methods respectively. The pore volumes $\mathrm{V}_{3}$ (pore volume greater than $50 \mathrm{~nm}$ in diameter, macropores), $\mathrm{V}_{2}$ (pore volume greater than $7.5 \mathrm{~nm}$ and less than $50 \mathrm{~nm}$ in diameter, mesopores) and $\mathrm{V}_{1}$, pores smaller than $7.5 \mathrm{~nm}$ [as estimated from $\left.\mathrm{V}_{1}=\mathrm{V}_{\mathrm{T}}-\left(\mathrm{V}_{2}+\mathrm{V}_{3}\right)\right]$ as estimated from mercury porosimetry are also listed in Table 1. The zero point charge $\left(\mathrm{pH}_{\mathrm{zpc}}\right)$ is defined as the $\mathrm{pH}$ of the suspension at which the surface charge density $\sigma_{o}=0$. The $\sigma_{\mathrm{o}}$ as a function of $\mathrm{pH}$ on activated carbons was determined using the procedure described by Schawrz et al. (1984). A conductometric method developed by James and Parks (1982) was used to determine the total number of acidic groups (including carboxyl, lactonic, sulphonic and phenolic groups) on the adsorbent surface. The carboxyl and phenolic acid groups were estimated using the methods proposed by Boehm and Voll (1970). The surface and physical properties of the SA-C and SA-S-C are given in Table 1.

Preliminary studies showed that the required sulphur concentration on the carbon surface could be consistently obtained under the following conditions:

- $\quad 2.3 \%$ sulphur content in SA-S-C [SA-S(2.3)-C]: flow time, 30 min for $\mathrm{SO}_{2}$ and $90 \mathrm{~min}$ for $\mathrm{H}_{2} \mathrm{~S}$; heating rate, $10^{\circ} \mathrm{C} / \mathrm{min}$ from 30 to $400^{\circ} \mathrm{C}$.

- $\quad 6.8 \%$ sulphur in SA-S-C [SA-S(6.8)-C]: flow time, 60 min for $\mathrm{SO}_{2}$ and $60 \mathrm{~min}$ for $\mathrm{H}_{2} \mathrm{~S}$; heating rate, $10^{\circ} \mathrm{C} / \mathrm{min}$ from 30 to $400^{\circ} \mathrm{C}$.

- $8.9 \%$ sulphur in SA-S-C [SA-S(8.9)-C]: flow time, 90 min for $\mathrm{SO}_{2}$ and $30 \mathrm{~min}$ for $\mathrm{H}_{2} \mathrm{~S}$; heating rate, $10^{\circ} \mathrm{C} / \mathrm{min}$ from 30 to $400^{\circ} \mathrm{C}$.

\section{Adsorption studies}

Batch adsorption experiments were carried out by shaking $0.1 \mathrm{~g}$ of carbon with $50 \mathrm{~cm}^{3}$ aqueous solution of $\mathrm{Cd}(\mathrm{II})$ of the desired concentration at various retention times in a temperature-controlled water-bath shaker (Remi, India make). The $\mathrm{pH}$ and ionic strength $(0.01 \mathrm{M})$ of the solutions were adjusted to constant values. 
Continuous mixing was provided during the experiments with a constant agitation speed of $200 \mathrm{r} / \mathrm{min}$. Kinetic studies were carried out at constant $\mathrm{pH}$ with an initial concentration range from 50 to $400 \mathrm{mg} / \mathrm{dm}^{3}$ and adsorbent dose from 2 to $10 \mathrm{~g} / \mathrm{dm}^{3}$. After shaking, the samples were withdrawn at suitable time intervals, filtered through a $0.45 \mu \mathrm{m}$ microporous membrane filter and then analysed for Cd(II) concentration with an atomic absorption spectrophotometer (Perkin Elmer 2380). For the isotherm studies, $0.1 \mathrm{~g}$ of activated carbon was put into $50 \mathrm{~cm}^{3}$ solutions of various concentrations of Cd(II) (50 to $\left.1000 \mathrm{mg} / \mathrm{dm}^{3}\right)$. The flasks were shaken for $5 \mathrm{~h}$ to attain equilibrium. A known volume of the solution was removed and filtered for $\mathrm{Cd}(\mathrm{II})$ analysis. The amount of $\mathrm{Cd}(\mathrm{II})$ adsorbed was determined by the difference between the initial and the equilibrium concentrations. Effect of $\mathrm{pH}$ on the adsorption of $\mathrm{Cd}(\mathrm{II})$ was studied by varying the $\mathrm{pH}$ from 2.0 to 10.0 . The effect of temperature on kinetics and adsorption equilibria was studied by varying temperature from 30 to $60^{\circ} \mathrm{C}$. All experiments were duplicated and showed differences of less than $5.0 \%$.

Similar batch experiments were carried out using commercial activated carbon (CAC) for comparison, obtained from E.Merck India Ltd. No pretreatment was given to the CAC and it was used as received in the experiments. The surface and physical properties of the CAC were also determined: surface area, $284.0 \mathrm{~m}^{2} / \mathrm{g}$; porosity, $0.43 \mathrm{~cm}^{3} / \mathrm{g}$; density, $0.92 \mathrm{~g} / \mathrm{cm}^{3}$; total acidic groups, 2.3 meq/g; carboxyl groups, $0.57 \mathrm{meq} / \mathrm{g}$; phenolic acidic groups, 0.28 $\mathrm{meq} / \mathrm{g}$; cation exchange capacity, $4.02 \mathrm{meq} / \mathrm{g}$ and $\mathrm{pH}_{\mathrm{zpc}}, 5.8$.

\section{Desorption and regeneration studies}

Regeneration of the activated carbon and recovery of the adsorbed $\mathrm{Cd}(\mathrm{II})$ were carried out by shaking the spent adsorbent material in $0.2 \mathrm{M} \mathrm{HCl}$ for a period of $5 \mathrm{~h}$. After attaining equilibrium, the sorbent was filtered and washed with distilled water. It was further dried at $80^{\circ} \mathrm{C}$ for $2 \mathrm{~h}$. The sorbent sample thus regenerated was reused for adsorption purposes. The loading and regeneration cycles were repeated three times. After each cycle the sorbent was washed with distilled water and dried.

\section{Results and discussion}

\section{Adsorbent characterisation}

The possible assignments of the observed peaks in the FTIR spectra of SA-C and SA-S(8.9)-C samples are furnished in Table 2. The asymmetric absorption bands observed at $3764 \mathrm{~cm}^{-1}$ for SA-C and at $3762 \mathrm{~cm}^{-1}$ for SA-S(8.9)-C indicate the presence of exchangeable $\mathrm{OH}^{-}$groups on both carbons. The IR spectra show bands at 1600 and $1608 \mathrm{~cm}^{-1}$ for SA-C and SA-S(8.9)-C, respectively, indicating the presence of conjugated hydrogen bonded carbonyl groups as suggested by Hallum and Drushell (1958). The carbons also contain carboxyl [bands at $1724 \mathrm{~cm}^{-1}$ for SA-C and $1730 \mathrm{~cm}^{-1}$ for SA-S(8.9)-C] functional groups. Additional peaks at 1167,1 111 and $460 \mathrm{~cm}^{-1}$ in the spectrum of SA-S(8.9)-C represent the $\mathrm{C}=\mathrm{S}, \mathrm{S}=\mathrm{O}$ and $\mathrm{S}-\mathrm{S}$ stretching vibrations due to the sulphur groups bonded to activated carbon (Nakanishi and Solamon, 1977).

The experimental results of surface titrations in $0.01 \mathrm{M} \mathrm{NaCl}$ on steam-activated and steam-activated sulphurised carbons with 2.3, 6.8 and $8.9 \%$ sulphur content are compared in Fig.1.The SA$\mathrm{C}$ displays a zero point charge at $\mathrm{pH}_{\mathrm{zpc}}=5.8$; at $\mathrm{pH}$ above that value the surface of the carbon has a negative charge, below that $\mathrm{pH}$ the carbon has a positive charge. The $\mathrm{pH}_{\text {zpc }}$ of SA-C (5.8) was decreased to 5.5, 4.7 and 4.3 respectively by the loading of 2.3, 6.8 and $8.9 \%$ of sulphur content, which indicates that the surface of

\begin{tabular}{|c|c|l|}
\hline \multicolumn{2}{|c|}{$\begin{array}{c}\text { TABLE 2 } \\
\text { Some fundamental IR absorption frequencies of } \\
\text { sulphurised [SA-S(8.9)-C] and sulphur-free activated } \\
\text { carbons }\end{array}$} \\
\cline { 1 - 2 } Band position (cm ${ }^{-1}$ ) & Possible assignments \\
\cline { 1 - 2 } SA-C & SA-S(8.9)-C & \\
\cline { 1 - 2 } 3764 & 3762 & O-H stretching of hydroxyl group \\
2925 & 2925 & C=C-H stretching \\
2854 & 2854 & C=C-H stretching \\
1724 & 1730 & C=O stretching of -COOH group \\
1600 & 1608 & C=O stretching of carbonyl group \\
1357 & 1360 & C-H deforming \\
- & 1167 & C=S stretching \\
- & 1111 & S=O stretching \\
- & 460 & S-S stretching \\
\hline
\end{tabular}

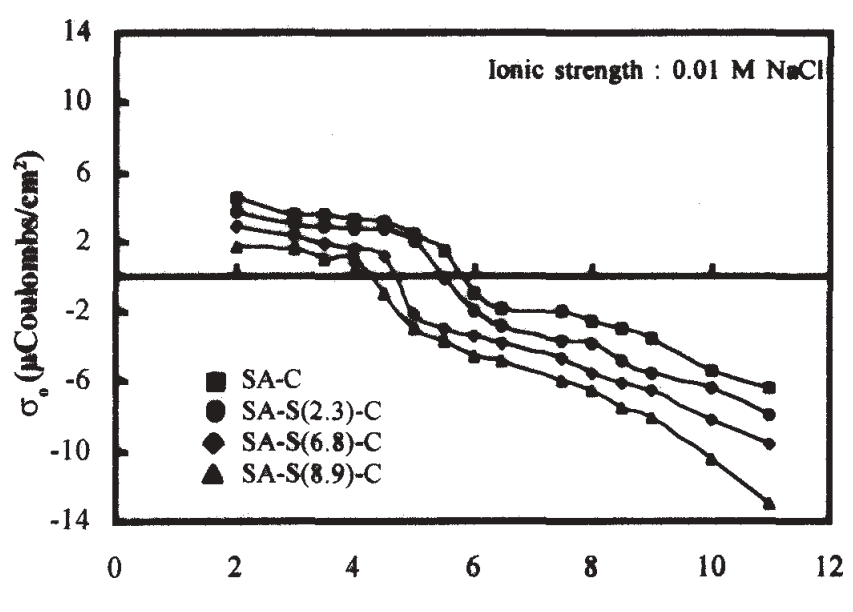

Figure 1

Effect of $\mathrm{pH}$ on the surface charge density of different activated carbons

SA-C has been modified after steam activation in the presence of $\mathrm{SO}_{2}$ and $\mathrm{H}_{2} \mathrm{~S}$. At any $\mathrm{pH}$ higher than the $\mathrm{pH}_{\mathrm{zpc}}$ the charge on the sulphurised carbons is lower than on the sulphur-free carbons. Increasing sulphur content resulted in an increase of sulphonic acid groups $\left(-\mathrm{SO}_{3} \mathrm{H}\right)$ on the activated carbons. The sulphonic acid groups have a lower $\mathrm{pK}_{\mathrm{a}}$ than normal carboxylic acids and hence the $\mathrm{pH}_{\text {zpc }}$ decreases in the same way as samples with higher sulphur content. As shown in the figure, the increased negative charge caused by sulphur enrichment is significant and would be expected to alter the adsorption properties of the carbons due to electrostatic effects. Although sulphurised carbons contain sulphur groups or linkages only, the surface area and porosity values remain considerably higher with respect to SA-C. This suggests that most of the functional groups or pores are not reacted or clogged with sulphur atoms.

\section{Effect of pH on $\mathrm{Cd}(\mathrm{II})$ adsorption}

Figure 2 shows the percentage of adsorbed Cd(II) vs. pH over the range of 2.0 to 10.0 for SA-S-C, SA-C and CAC. The percentage adsorption of metal ions increased with an increase in $\mathrm{pH}$ up to a certain value and then decreased with further increase of $\mathrm{pH}$. It is 


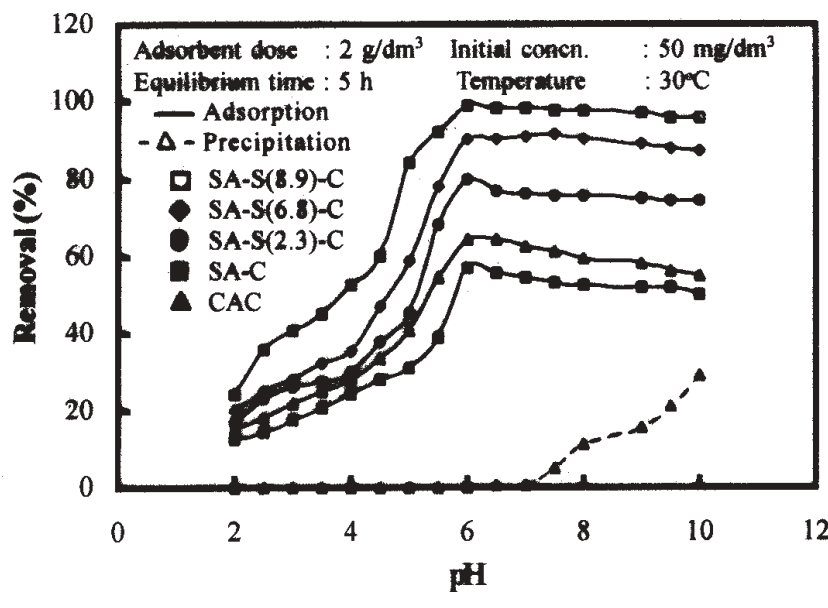

Figure 2

Effect of $\mathrm{pH}$ on the removal of $\mathrm{Cd}(\mathrm{II})$ by activated carbons

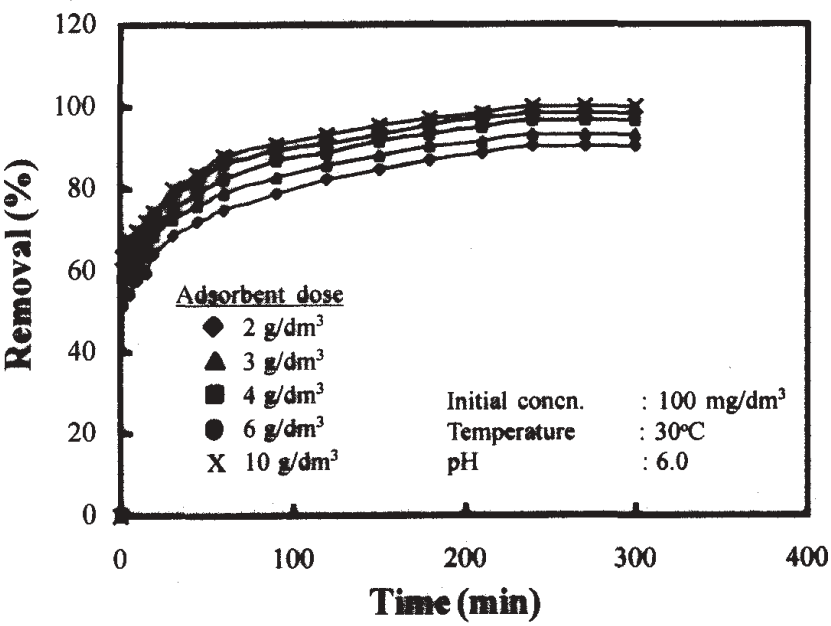

Figure 3

Variation of Cd(II) removal versus time at different SA-S(8.9)-C doses

clear that sulphurised activated carbons are effective for the quantitative removal of Cd(II) over the $\mathrm{pH}$ range 5.0 to 9.0. Sulphur-free carbon, however, is effective within a narrow range of 6.0 to 8.0. The maximum adsorption of $98.8 \%(24.70 \mathrm{mg} / \mathrm{g}), 90.6 \%(22.65$ $\mathrm{mg} / \mathrm{g}), 79.6 \%(19.90 \mathrm{mg} / \mathrm{g}), 64.2 \%(16.05 \mathrm{mg} / \mathrm{g})$ and $56.8 \%$ $(14.20 \mathrm{mg} / \mathrm{g})$ took place by SA-S(8.9)-C, SA-S(6.8)-C, SA-S(2.3)$\mathrm{C}, \mathrm{CAC}$ and SA-C, respectively at $\mathrm{pH} 6.0$ from an initial concentration of $50 \mathrm{mg} / \mathrm{dm}^{3}$. The data clearly show that sulphurised carbons are 1.4 to 1.7 times more effective than sulphur-free carbon for the removal of $\mathrm{Cd}(\mathrm{II})$. For comparison, $\mathrm{Cd}(\mathrm{II})$ removal by hydroxide precipitation as a function of $\mathrm{pH}$ with no adsorbent is also given. The experimental precipitation curves which show a sharp decrease in concentration of Cd(II) ions in solution, suggest that $\mathrm{Cd}(\mathrm{II})$ is precipitating from the solution at this concentration, well before adsorption is complete. However, at any $\mathrm{pH}$ metal removal by adsorption is very much greater than hydroxide precipitation.

The effect of $\mathrm{pH}$ can be explained in terms of $\mathrm{pH}_{\mathrm{zpc}}$ of the adsorbent and species of $\mathrm{Cd}(\mathrm{II})$ formed in the solution. The surface charge is a function of $\mathrm{pH}$. The $\mathrm{pH}$ with which the charge of the solid surface is zero is referred to as the zero point of charge $\left(\mathrm{pH}_{\mathrm{zpc}}\right)$. Above $\mathrm{pH}_{\mathrm{zpc}}$ the surface charge of the adsorbent is negative. Perusal of the literature on Cd(II) speciation diagram (Ramos et al., 1997) shows that the dominant $\mathrm{Cd}(\mathrm{II})$ species at $\mathrm{pH}>8.0$ is $\mathrm{Cd}(\mathrm{OH})_{2}$ and at $\mathrm{pH}<8.0$ is $\mathrm{Cd}^{2+}$ and $\mathrm{Cd}(\mathrm{OH})^{+}$. The maximum sorption efficiency in the $\mathrm{pH}$ range of 5.0 to 8.0 may be due to the interaction of $\mathrm{Cd}^{2+}$ and $\mathrm{Cd}(\mathrm{OH})^{+}$with surface sulphur groups present in sulphurised carbon. According to the Pearson theory (Pearson, 1988) during acid base reaction, hard acids prefer to interact with hard bases and soft acids with soft bases. Positively charged Cd(II) species are soft acids and as a rule the interaction of $\mathrm{Cd}^{2+}$ and $\mathrm{Cd}(\mathrm{OH})^{+}$with surface sulphur groups (soft bases) is likely favoured at the $\mathrm{pH}$ range of 5.08.0. In addition to sulphur groups, the carbon containing carboxyl and hydroxyl groups are also responsible for the sorption of $\mathrm{Cd}(\mathrm{II})$ ions. At low $\mathrm{pH}$ particularly below $\mathrm{pH}_{\mathrm{zpc}}$ the positively charged $\mathrm{Cd}^{2+}$ and $\mathrm{Cd}(\mathrm{OH})^{+}$species present in the solution may exchange with $\mathrm{H}^{+}$from peripheral - $\mathrm{COOH}$ or hydroxyl groups of carbon. It was shown that final $\mathrm{pH}$ of the solution is always less than the initial $\mathrm{pH}$ at $\mathrm{pH}$ range between 2.0 and $\mathrm{pH}$ of zero point charge.

Decrease in removal of Cd(II) ions at very low $\mathrm{pH}$ is apparently due to the higher concentrations of $\mathrm{H}^{+}$ions present in the mixture which compete with the $\mathrm{Cd}^{2+}$ for the adsorption sites of carbon. A decreasing trend in adsorption was also observed at very high $\mathrm{pH}$ and this may be due to the formation of soluble hydroxy complexes (Raji et al., 1997).

The lowest $\mathrm{pH}_{z \mathrm{pc}}$ shown by SA-S(8.9)-C, indicates that it has more acidic functional groups (Table 1) than the rest of carbons, or in other words, it is less basic, which is advantageous for the removal of metal cations. Even though sulphurised activated carbons of various sulphur content were effective for the removal of Cd(II), SA-S(8.9)-C appeared to be more efficient. As such subsequent experiments were carried out using sulphurised carbon having $8.9 \%$ of sulphur content.

The extent of $\mathrm{Cd}(\mathrm{II})$ adsorption onto $\mathrm{CAC}$ as a function of $\mathrm{pH}$ for an initial concentration of $50 \mathrm{mg} / \mathrm{dm}^{3}$ is also shown in Fig. 2 . The percentage adsorption increased with increasing $\mathrm{pH}$ up to a certain value and then decreased with further increasing $\mathrm{pH}$. The maximum adsorption of $64.2 \%$ was observed at $\mathrm{pH}$ 6.0. Above and below this $\mathrm{pH}$ the adsorption was found to be considerably lower.

\section{Effect of initial concentration and adsorbent dose}

Several experiments were conducted in order to normalise the procedure for the determination of the adsorption isotherm and to study the kinetic behaviour. The kinetic data for the removal of $\mathrm{Cd}(\mathrm{II})$ by adsorption vs. contact time for a fixed initial concentration of $100 \mathrm{mg} / \mathrm{dm}^{3}\left(\mathrm{C}_{\mathrm{o}}\right)$ with five different doses $\left(\mathrm{W}_{\mathrm{s}}\right)$ of SA-S-C varying between $2 \mathrm{~g} / \mathrm{dm}^{3}$ and $10 \mathrm{~g} / \mathrm{dm}^{3}$ are presented in Fig. 3. The rate of $\mathrm{Cd}(\mathrm{II})$ sorption was very high initially and decreased markedly after $1 \mathrm{~h}$. A quasi-stationary state was obtained within $5 \mathrm{~h}$ of shaking and is independent of adsorbent dose. Based on the experimental results an equilibrium contact time of $5 \mathrm{~h}$ was used in all further experiments. The $\mathrm{Cd}(\mathrm{II})$ removal from its solution is influenced by $\mathrm{W}_{\mathrm{s}}$. It was noted that at any time for a given $\mathrm{C}_{0}$ value the $\mathrm{Cd}(\mathrm{II})$ removal increased with increase in $\mathrm{W}_{\mathrm{s}}$ values. This is because at higher dose of adsorbent due to increased surface area, more adsorption sites are available causing higher removal of $\mathrm{Cd}(\mathrm{II})$. Removal of Cd(II) on SA-S(8.9)-C as a function of time at different initial concentrations and adsorbent doses was also studied and in all cases the shape of the removal vs. time curves was similar to that observed in Fig. 3. Based on studies conducted on the effect of contact time for the removal Cd(II) with different initial concentrations and adsorbent doses showed that an equilibrium time of $5 \mathrm{~h}$ is sufficient to reach equilibrium. The saturation period of the adsorption is entirely independent of the initial concentra- 
tion. The effect of variation in these parameters on $\mathrm{Cd}(\mathrm{II})$ removal was quantified in terms of their plateau $(5 \mathrm{~h})$ values. The dependence of the process of $\mathrm{Cd}$ (II) removal from different initial concentrations (50 to $400 \mathrm{mg} / \mathrm{dm}^{3}$ ) with different adsorbent doses is illustrated in Fig. 4. The increase in initial Cd(II) concentration decreased the percentage removal and increased the amount of $\mathrm{Cd}(\mathrm{II})$ uptake per unit mass of the adsorbent $(\mathrm{mg} / \mathrm{g})$. The removal ofCd(II) ions decreased from $98.8 \%(24.70 \mathrm{mg} / \mathrm{g})$ to $48.2 \%(96.38$ $\mathrm{mg} / \mathrm{g}$ ) by increasing the concentrations from 50 to $400 \mathrm{mg} / \mathrm{dm}^{3}$ at an adsorbent dose of $2 \mathrm{~g} / \mathrm{dm}^{3}$. This is because at higher initial concentrations the ratio of initial number of moles of $\mathrm{Cd}(\mathrm{II})$ to the available surface area is high, hence fractional adsorption becomes dependent on initial concentration. For fixed adsorbent dose, the total available adsorption sites are limited thereby adsorbing almost the same amount of sorbate thus resulting in a decrease in percentage removal of the adsorbate corresponding to an increase initial sorbate concentration.

\section{Adsorption dynamics}

Kinetics of adsorption, in terms of solute uptake rate, which governs the residence time, is one of the important characteristics defining the efficiency of adsorption. Earlier workers proposed a surface complexation mechanism for heavy metal adsorption onto activated carbon. By virtue of its surface composition, sulphurised activated carbon is assumed to have $\mathrm{C}=\mathrm{S}, \mathrm{S}=\mathrm{O}, \mathrm{S}-\mathrm{S}, \mathrm{C}=\mathrm{O}, \mathrm{C}-\mathrm{OH}$

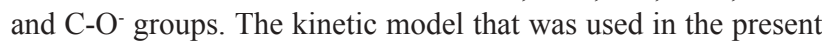
study to describe the reaction rate was based on the assumption that the adsorption of $\mathrm{Cd}(\mathrm{II})$ onto carbon is a surface complexation reaction and can be represented as:

$$
\mathrm{P}+\mathrm{M} \underset{\mathrm{k}^{\mathrm{k}}}{\stackrel{\mathrm{k}}{\rightleftharpoons}} \mathrm{PM}
$$

where:

$\mathrm{P}$ is the active site occupied on the adsorbent,

$\mathrm{M}$ is the concentration of free metal in solution,

$\mathrm{PM}$ is the concentration of metal bound to adsorbent

$\mathrm{k}$ and $\mathrm{k}$ ' are the adsorption rate and desorption rate constants, respectively.

The rate equation for the reaction can be written as:

$$
\frac{\mathrm{d}(\mathrm{P})_{\mathrm{t}}}{\mathrm{dt}}=\mathrm{k}\left[(\mathrm{P})_{\mathrm{o}}-(\mathrm{P})_{\mathrm{t}}\right]^{2}
$$

where:

$(\mathrm{P})_{\mathrm{t}}$ and $(\mathrm{P})_{\mathrm{o}}$ are the number of active sites occupied on the sorbent at any time $t$ and the number of equilibrium sites available on the adsorbent.

The rate constant $\mathrm{k}$ of the adsorption of $\mathrm{Cd}(\mathrm{II})$ on activated carbon was determined using the following equation developed by Ho and McKay (2000).

$$
\frac{\mathrm{t}}{\mathrm{q}_{\mathrm{t}}}=\frac{1}{\mathrm{kq}_{\mathrm{e}}^{2}}+\frac{\mathrm{t}}{\mathrm{q}_{\mathrm{e}}}
$$

where:

$\mathrm{q}_{\mathrm{e}}$ is the amount adsorbed at equilibrium $(\mathrm{mg} / \mathrm{g})$ and

$\mathrm{q}_{\mathrm{t}}$ is the amount adsorbed at time $\mathrm{t}(\mathrm{mg} / \mathrm{g})$.

The kinetic plots of $t / q_{t}$ vs. $t$ for Cd(II) removal at different concentrations and temperatures are presented in Fig. 5. The relationship is linear, and the correlation coefficient (Table 3), suggests a strong relationship between the parameters and also

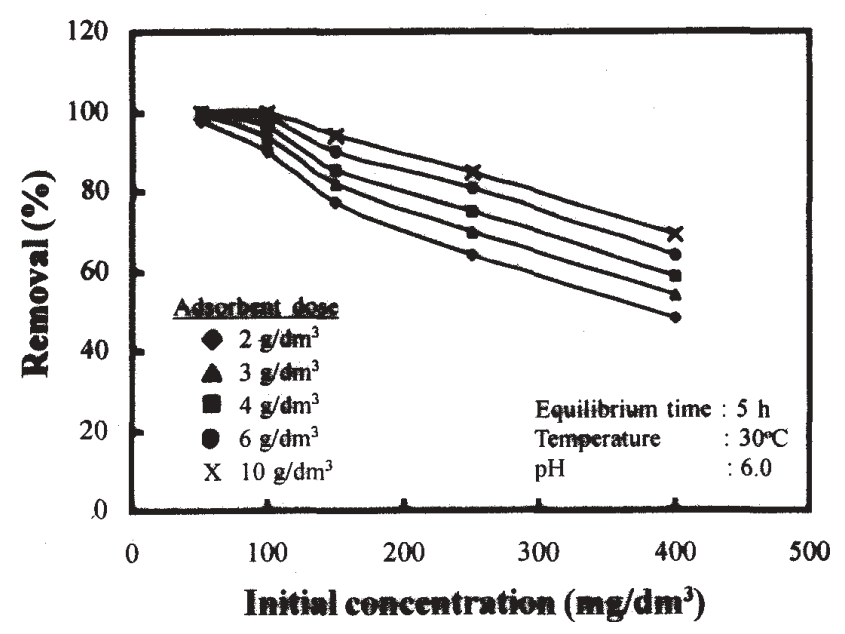

Figure 4

Variation of Cd(II) removal vs. initial concentration at different $S A-S(8.9)-C$ doses

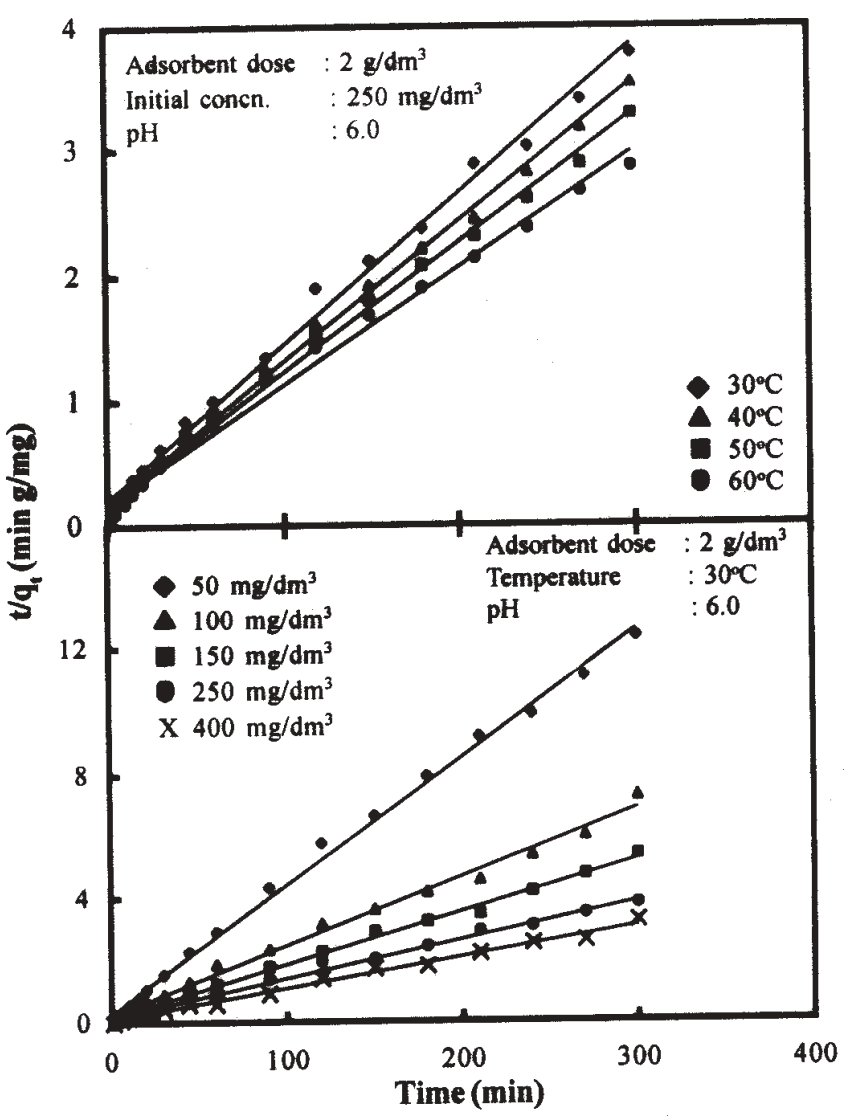

Figure 5

Pseudo-second-order kinetic plots for the adsoption of $\mathrm{Cd}(\mathrm{II})$ on SA-S(8.9)-C at different initial concentrations and temperatures

explains that the process of adsorption follows pseudo-secondorder kinetics. The product $\mathrm{kq}_{\mathrm{e}}{ }^{2}$ is the initial sorption rate represented as $\mathrm{h}=\mathrm{kq}_{\mathrm{e}}{ }^{2}$. From Table 3, it can be shown that the initial adsorption rate ' $h$ ' is increased with increase in metal concentration. Table 3 shows that the equilibrium sorption capacity, $q_{e}$, increased from 24.39 to $96.15 \mathrm{mg} / \mathrm{g}$ as the initial concentration varied from 50 to $400 \mathrm{mg} / \mathrm{dm}^{3}$. The values of $\mathrm{k}$, however, were 


\begin{tabular}{|c|c|c|c|c|}
\hline \multicolumn{5}{|c|}{$\begin{array}{c}\text { TABLE } 3 \\
\text { Kinetic parameters for the adsorption of Cd(II) ontoSA-S(8.9)-C }\end{array}$} \\
\hline Variable & $\begin{array}{c}\text { k } \\
(\mathrm{g} / \mathrm{mg} \cdot \min )\end{array}$ & $\underset{(m g / g)}{q_{e}}$ & $\begin{array}{c}\mathrm{h} \\
(\mathrm{mg} / \mathrm{g} \cdot \min )\end{array}$ & $\mathbf{R}^{2}$ \\
\hline \multicolumn{5}{|l|}{$\begin{array}{l}\text { Concentration } \\
\left(\mathrm{mg} / \mathrm{dm}^{3}\right)\end{array}$} \\
\hline 50 & $7.88 \times 10^{-3}$ & 24.39 & 4.69 & 0.998 \\
\hline 100 & $4.74 \times 10^{-3}$ & 45.25 & 9.71 & 0.998 \\
\hline 150 & $3.40 \times 10^{-3}$ & 57.47 & 11.24 & 0.999 \\
\hline 250 & $2.33 \times 10^{-3}$ & 79.37 & 14.71 & 0.997 \\
\hline 400 & $1.64 \times 10^{-3}$ & 96.15 & 15.15 & 0.999 \\
\hline \multicolumn{5}{|l|}{ Temperature $\left({ }^{\circ} \mathrm{C}\right)$} \\
\hline 30 & $2.33 \times 10^{-3}$ & 79.37 & 14.71 & 0.997 \\
\hline 40 & $2.80 \times 10^{-3}$ & 86.21 & 20.83 & 0.997 \\
\hline 50 & $3.58 \times 10^{-3}$ & 93.46 & 31.25 & 0.995 \\
\hline 60 & $4.46 \times 10^{-3}$ & 101.01 & 45.45 & 0.991 \\
\hline
\end{tabular}

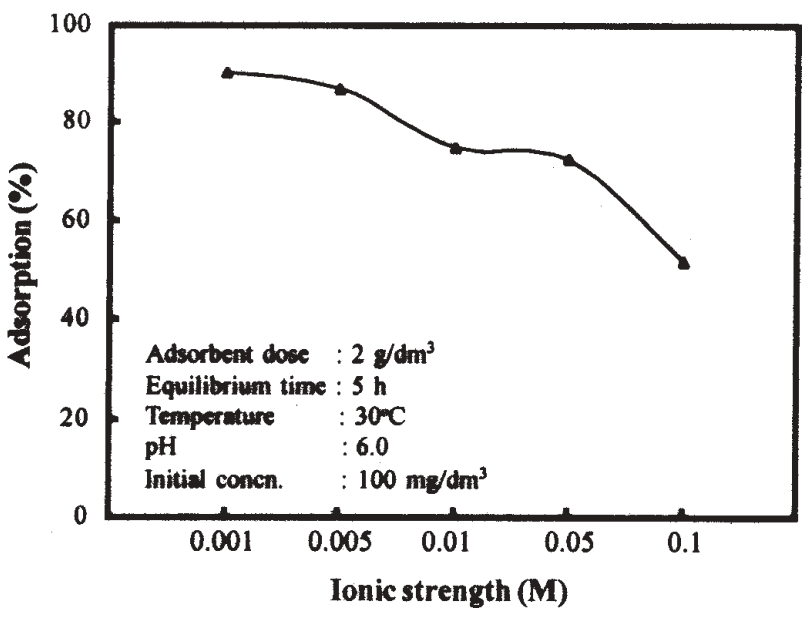

Figure 6

Effect of ionic strength on the adsorption of $\mathrm{Cd}(\mathrm{II})$ on $S A-S(8.9)-C$

found to decrease with increase of initial concentration. Earlier workers also presented similar results for the adsorption of $\mathrm{Hg}$ (II) , Ni(II) and Cr(VI) onto chitosan (McKay et al., 1986) moss peat (Ho et al., 1995) and activated carbon (Raji and Anirudhan, 1997) respectively. Increasing the metal concentration in solution seems to reduce the diffusion of metal ions in the boundary layer and to enhance the diffusion in the solid. Another cause could be due to the progressive decrease in covalent interactions, relative to electrostatic interactions of the sites with lower affinity for $\mathrm{Cd}^{2+}$ with an increase in initial $\mathrm{Cd}(\mathrm{II})$ concentration. The linearised $\mathrm{k}$ and $\mathrm{C}_{\mathrm{o}}$ values as a double logarithmic plot showed a correlation coefficient of 0.98 , the relationship between $\mathrm{k}$ and $\mathrm{C}_{\mathrm{o}}$ being of the type:

This equation can be used to predict the $\mathrm{k}$ values for any concentration within the test limits.

The perusal of data on Table 3 reveals that for the equilibrium time, the metal ion adsorbed $\mathrm{q}_{e}$ is higher for higher temperature and greater values of initial metal ion concentration. The values of h and $\mathrm{k}$ increase with increase in temperature. The increase in rate of adsorption with increasing temperature is described by the Arrhenius equation:

$$
\ln \mathrm{k}=\ln \mathrm{A}_{\mathrm{o}}-\frac{\mathrm{E}_{\mathrm{a}}}{\mathrm{RT}}
$$

where:

$\mathrm{A}_{\mathrm{o}}$ is the temperature independent factor called "frequency factor",

$\mathrm{k}$ is the rate constant and

$\mathrm{E}_{\mathrm{a}}$ is the activation energy.

A linear relationship was obtained between $\ln \mathrm{k}$ and $1 / T$. The values of $A_{o}$ and $E_{a}$ were calculated from the intercept and slope of the $\ln \mathrm{k}$ versus $1 / \mathrm{T}$ plot (Figure not shown) and were found to be $3.24 \mathrm{~g} / \mathrm{mg}$ min and $18.28 \mathrm{~kJ} / \mathrm{mol}$ respectively. The value $18.28 \mathrm{~kJ} / \mathrm{mol}$ in the present study indicates a chemical sorption process involving weak interactions between sorbent and sorbate (Ho et al., 2001).The relatively low $\mathrm{E}_{\mathrm{a}}$ value suggests that the adsorption has a low potential energy barrier.

\section{Effect of ionic strength}

Figure 6 shows the influence of ionic strength on the adsorption of $\mathrm{Cd}$ by sulphurised activated carbon. It is evident that the adsorption of $\mathrm{Cd}(\mathrm{II})$ decreased in the presence of $\mathrm{NaCl}$. The percentage of adsorption decreased from 90.1 to $51.8 \%$ with an increase in ionic strength from 0.001 to $0.1 \mathrm{M} \mathrm{NaCl}$. Adsorption is sensitive to the change in ionic strength if electrostatic attraction is a significant mechanism. Thus the results indicate that electrostatic attraction plays an important role in the adsorption of Cd(II) onto activated carbon (Das and Bandyopadyay, 1991). At high ionic strength, the increased amount of $\mathrm{NaCl}$ can help to swamp the surface of the carbon, which decreases Cd(II) ion's access to the carbon surface for adsorption. According to the Surface Chemistry Theory developed by Guoy and Chapman (Osipow, 1972), when solid adsorbent is in contact with sorbate species in solution, they are bound to be surrounded by an electrical diffused double layer, the thickness of which is significantly expanded by the presence of electrolyte. Such expansion inhibits the adsorbent particles and Cd(II) species from approaching each other more closely and, through the decreased electrostatic attraction, leads to the decreased uptake of Cd(II) ions.

The modification of the Cd(II) species is another important factor leading to a decrease in adsorption with increase in ionic strength. It has been reported by earlier workers (Benjamin and Leckie, 1982) that an increase in chloride concentration reduced the $\mathrm{Cd}^{2+}$ and $\mathrm{Cd}(\mathrm{OH})^{+}$species due to the formation of chlorocomplexes. Cadmium forms some stable chloro-complexes, namely $\mathrm{CdCl}^{+}, \mathrm{CdCl}_{2}$ and $\mathrm{CdCl}_{3}{ }^{-}$, which do not appear to be adsorbed to the same extent as $\mathrm{Cd}^{2+}$ and $\mathrm{Cd}(\mathrm{OH})^{+}$ions.

\section{Effect of co-ions}

The effect of $\mathrm{Cu}(\mathrm{II}), \mathrm{Hg}(\mathrm{II})$ and $\mathrm{Pb}$ (II) on the uptake of $\mathrm{Cd}(\mathrm{II})$ by the SA-S(8.9)-C was investigated. Batch experiments were conducted using $50 \mathrm{~cm}^{3}$ of Cd(II) solution having co-ions in the molar ratio of $1: 1$ and $1: 2$. The percentage adsorption of $\mathrm{Cd}(\mathrm{II})$ from solution was $98.8 \%$ in the absence of any co-ions. The adsorption decreases to $83.8,79.1$ and $72.1 \%$ respectively; when $\mathrm{Cu}(\mathrm{II})$, $\mathrm{Hg}(\mathrm{II})$ and $\mathrm{Pb}(\mathrm{II})$ ions are present in the 1:1 ratio. As the molar ratio 
TABLE 4

Langmuir constants and thermodynamic parameters for the adsorption of $\mathrm{Cd}$ (II) onto SA-S(8.9)-C

\begin{tabular}{|c|c|c|c|c|c|c|c|}
\hline \multirow{2}{*}{$\begin{array}{c}\text { Tempe- } \\
\text { rature } \\
\left({ }^{\circ} \mathrm{C}\right)\end{array}$} & \multicolumn{4}{|c|}{ Langmuir constants } & \multirow[t]{2}{*}{$\mathbf{R}^{2}$} & \multicolumn{2}{|c|}{$\begin{array}{c}\text { Thermodynamic } \\
\text { parameters }\end{array}$} \\
\hline & $\mathrm{Q}^{\circ}(\mathrm{mg} / \mathrm{g})$ & $\begin{array}{c}95 \% \text { confidence } \\
\text { limit }\end{array}$ & b $\left(\mathrm{dm}^{3} / \mathrm{mg}\right)$ & $\begin{array}{c}95 \% \text { confidence } \\
\text { limit }\end{array}$ & & $\Delta \mathrm{G}(\mathrm{kJ} / \mathrm{mol})$ & $\Delta \mathrm{S}(\mathrm{J} / \mathrm{mol} / \mathrm{K})$ \\
\hline 30 & $149.93 \pm 5.44$ & $146.00-156.88$ & $0.161 \pm 0.015$ & $0.154-0.181$ & 0.988 & -0.89 & 93.77 \\
\hline 40 & $163.32 \pm 7.16$ & $158.30-172.62$ & $0.213 \pm 0.017$ & $0.199-0.241$ & 0.992 & -1.81 & 93.71 \\
\hline 50 & $172.81 \pm 4.17$ & $172.03-180.37$ & $0.317 \pm 0.028$ & $0.284-0.350$ & 0.991 & -2.73 & 93.64 \\
\hline 60 & $190.48 \pm 12.07$ & $184.52-206.66$ & $0.421 \pm 0.046$ & $0.380-0.463$ & 0.987 & -3.65 & 93.61 \\
\hline
\end{tabular}

increases to 1:2 even more reduction of $\mathrm{Cd}(\mathrm{II})$ removal yield was noticed. The experimental results show that a 72.2, 70.5 and 60.6 $\%$ reduction in $\mathrm{Cd}(\mathrm{II})$ removal was observed when $\mathrm{Cu}(\mathrm{II}), \mathrm{Hg}(\mathrm{II})$ and $\mathrm{Pb}$ (II) ions present at a molar ratio of 1:2. This reduction in $\mathrm{Cd}(\mathrm{II})$ adsorption might be due to a competitive ion effect between $\mathrm{Cd}(\mathrm{II})$ and co-ions for the adsorption sites on the carbon. Based on these experimental results, the $\mathrm{Pb}$ (II) ion may be a stronger competitive ion than $\mathrm{Hg}(\mathrm{II})$ and $\mathrm{Cu}(\mathrm{II})$ ions for $\mathrm{Cd}(\mathrm{II})$ removal by SA-S-C. The results can also be explained by the selectivity sequence of the most common cations on the adsorbent surface. It was observed that amongst the cations used, interference of $\mathrm{Pb}$ (II) ion is highest, followed by $\mathrm{Hg}(\mathrm{II})$ and $\mathrm{Cu}(\mathrm{II})$. The observed order of interference was the same as that of their increasing ionic radii, i.e. their decreasing hydrated ionic radii. The smaller the hydrated ionic radius, the greater its efficiency to active groups of the adsorbent. This suggests that the energy required in the dehydration of the metal ions, in order that they could occupy a site in the adsorbent, plays an important role in determining the selectivity series for the metal ions.

\section{Analysis of adsorption capacities by the Langmuir equation}

Sorption equilibrium is established when the concentration of metal in a bulk solution $\left(\mathrm{C}_{\mathrm{e}}\right)$ is in dynamic balance with that of the interface $\left(q_{e}\right)$. Figure 7 shows the experimental sorption isotherms for the $\mathrm{Cd}$ (II)-activated carbon system. It is seen that the adsorption density increases with increasing solution temperature. To determine the adsorption capacity of the activated carbon, a study of the adsorption isotherm was attempted by analysing adsorption data by a computer simulation technique to fit the Langmuir isotherm model. The model assumes uniform energies of adsorption onto the surface and no transmigration of adsorbate in the plane of the surface. The Langmuir isotherm is given by:

$$
\mathrm{q}_{\mathrm{e}}=\frac{\mathrm{bC}_{\mathrm{e}} \mathrm{Q}^{\mathrm{o}}}{1+\mathrm{bC}_{\mathrm{e}}}
$$

where:

$\mathrm{q}_{\mathrm{e}}$ is the amount of solute adsorbed per unit mass of adsorbent $(\mathrm{mg} / \mathrm{g})$,

$\mathrm{C}_{\mathrm{e}}$ is the equilibrium solution-phase concentration $\left(\mathrm{mg} / \mathrm{dm}^{3}\right)$, $\mathrm{Q}^{\circ}$ and $\mathrm{b}$ are Langmuir constants related to the maximum adsorption capacity corresponding to complete coverage of available adsorption sites $(\mathrm{mg} / \mathrm{g})$ and energy/intensity of adsorption respectively.

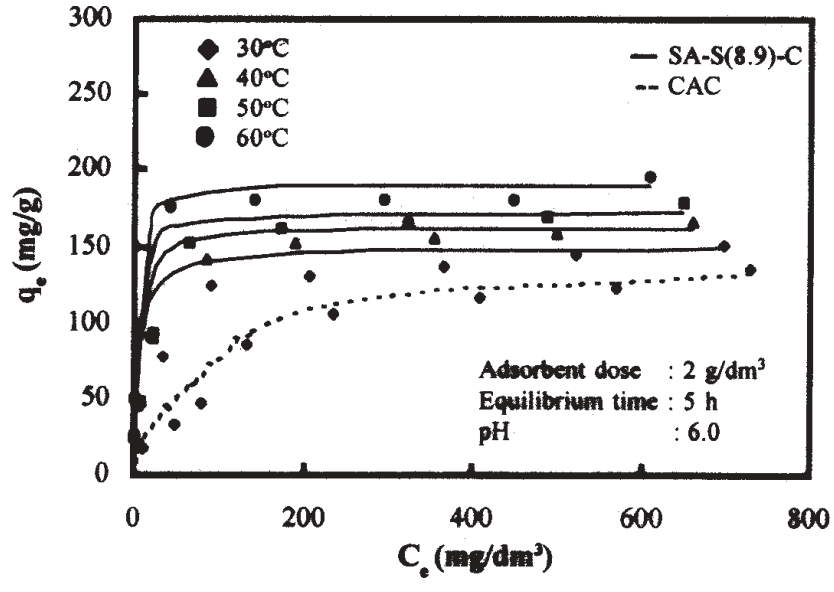

Figure 7

Plots of $q_{\mathrm{e}}$ vs. $C$ for the adsorption of Cd(II) on SA-S(8.9)-C and CAC. Lines are Langmuir model curves

The Langmuir parameters were obtained by fitting the experimental data to the linearised equation derived from Eq. (6):

$$
\frac{1}{\mathrm{q}_{\mathrm{e}}}=\frac{1}{\mathrm{Q}^{\mathrm{o} b C_{e}}}+\frac{1}{\mathrm{Q}^{\mathrm{o}}}
$$

The values of $Q^{\circ}$ and $b$ were calculated from the intercept and slope of the linear plots of $1 / \mathrm{q}_{\mathrm{e}}$ vs. $1 / \mathrm{C}_{\mathrm{e}}$ for different temperatures and are listed in Table 4 along with standard deviations, $95 \%$ confidence limiting values and thier coefficients of correlation $\left(\mathrm{R}^{2}\right)$. From the values obtained for the parameters the theoretical Langmuir curves were calculated and are plotted in Fig. 7. The good fit of the experimental data and the correlation coefficients $\left(\mathrm{R}^{2}\right)$ higher than 0.987 indicated the applicability of the Langmuir isotherm model. The Langmuir constants $\mathrm{Q}^{\circ}$ and $\mathrm{b}$ increased with temperature showing that adsorption capacity and intensity of adsorption are enhanced at higher temperatures and indicating the endothermic nature of adsorption. The increase in adsorption capacity with temperature suggested that the active, surface centres available for adsorption have increased with temperature. Another reason may be due to the change in pore size and enhanced rate of intraparticle diffusion of solute as diffusion is an endothermic process.

The change in apparent enthalpy $(\mathrm{H})$, free energy (" $\mathrm{G})$, and entropy ("S) of adsorption were calculated from the variations of the Langmuir constatnt, $\mathrm{b}\left(\mathrm{dm}^{3} / \mathrm{mol}\right)$ with change in temperature using the following equations: 


\begin{tabular}{|l|c|c|l|}
\hline \multicolumn{3}{|c|}{ Langmuir constants for the adsorption of Cd(II) onto different adsorbents } \\
\hline \multirow{2}{*}{ Adsorbent } & Langmuir constants & References \\
\cline { 2 - 3 } & $\mathbf{Q}^{\circ}(\mathbf{m g} / \mathbf{g})$ & b (dm $3 / \mathbf{m g})$ & \\
\hline \multirow{2}{*}{ Geothite } & 2.89 & 0.456 & Johnson (1990) \\
Straw-based activated carbon & 11.10 & - & Larsen and Schierup (1981) \\
Groundnut husk & 42.71 & 0.027 & Okieimen et al. (1991) \\
Activated bentonite & 16.50 & 1.860 & Pradas et al. (1994) \\
Coconut shell-based activated carbon & 124.76 & 0.020 & Budinova et al. (1994) \\
Apricot stone-based activated carbon & 134.88 & 0.044 & Budinova et al. (1994) \\
Bituminous coal & 6.47 & 0.015 & Singh and Rawat (1994) \\
Kimberlite tailings & 7.22 & 0.461 & Srinivasa Rao and Bandyopadyay (1995) \\
Sphagnum peat moss & 198.80 & 0.010 & Allen et al. (1992) \\
Fe(III)/Cr(III) hydroxide waste & 40.49 & 0.231 & Namasivayam and Ranganathan (1995) \\
Commercial activated carbon (F-400) & 8.21 & 0.380 & Ramos et al. (1997) \\
Commercial activated carbon (E. Merck) & 130.21 & 0.120 & Present study \\
SA-S(8.9)-C & 149.93 & 0.161 & Present study \\
\hline
\end{tabular}

\begin{tabular}{|c|c|c|}
\hline \multicolumn{3}{|c|}{ TABLE 6 } \\
\hline \multicolumn{3}{|c|}{ Desorption and regeneration data } \\
\hline Cycle & Adsorption, mg/g (\%) & Desorption, $\mathbf{~ g / g ~ ( \% ) ~}$ \\
\hline 1 & $24.38(97.5)$ & $23.02(94.4)$ \\
2 & $23.35(93.4)$ & $21.30(91.2)$ \\
3 & $22.03(88.1)$ & $19.12(86.8)$ \\
\hline
\end{tabular}

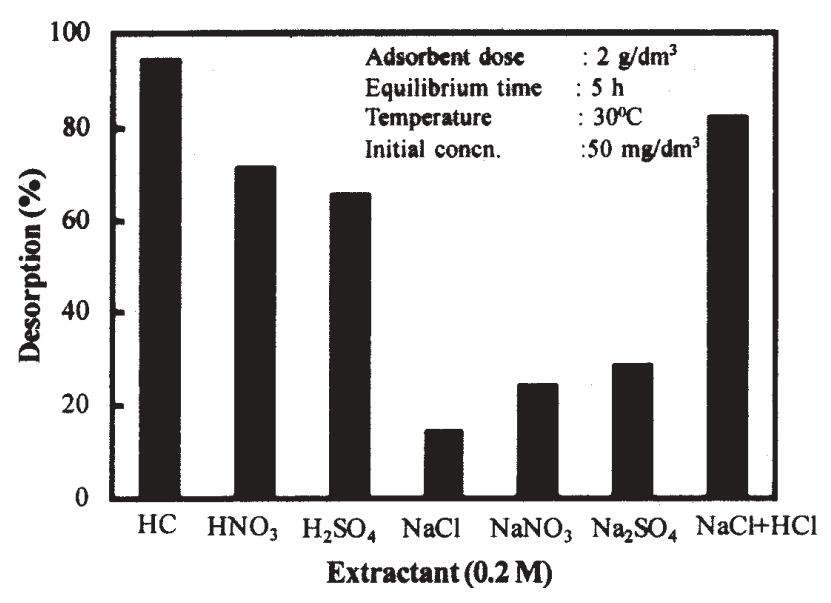

Figure 8

Effect of various extractants on the desorption of $\mathrm{Cd}(\mathrm{II})$ from spent $S A-S(8.9)-C$

$$
\begin{aligned}
& \ln b=\ln b^{\prime}-\frac{\Delta H}{R T} \\
& \ln b=-\frac{\Delta G}{R T} \\
& \Delta S=\frac{\Delta H-\Delta G}{T}
\end{aligned}
$$

where:

$\mathrm{R}$ is the gas law constant, and

b'is equal to $\Delta S / R$.

The plot of $\ln \mathrm{b}$ vs. 1/T was found to be linear (figure not shown) and $\mathrm{H}$ was computed from the slope. The positive value of $\mathrm{H}(27.52$ $\mathrm{kJ} / \mathrm{mol}$ ) reflects the endothermic nature of the process. The negative values of $\Delta \mathrm{G}$ (Table 4 ) indicate the process to be feasible and spontaneous. The amount adsorbed at equilibrium must increase with increasing temperature, because $\Delta \mathrm{G}$ decreases with increasing temperature of the solution. This explains why the negative values increase with increasing temperature. The positive values of $\Delta \mathrm{S}$ reflect the affinity of the carbon for Cd(II) and also suggest some structural changes in the adsorbate and adsorbent.

The specific surface area occupied by $\mathrm{Cd}$ (II) was calculated by the following equation (Viladkar et al., 1996):

$$
\mathrm{S}_{\mathrm{Cd}^{2+}}=6.023 \times 10^{-2} \mathrm{M}_{\mathrm{f}} \mathrm{A}_{\mathrm{m}}
$$

where:

$\mathrm{M}_{\mathrm{f}}$ is the amount of Cd(II) (mmol) adsorbed per $100 \mathrm{~g}$ of carbon when the surface is completely occupied by a monolayer of $\mathrm{Cd}(\mathrm{II})$.

$\mathrm{A}_{\mathrm{m}}$ is the cross-sectional area per molecule in $\AA^{2}$ on the surface.

The monolayer adsorption capacity $\left(\mathrm{Q}^{\circ}\right)$ for $\mathrm{Cd}(\mathrm{II})$ is $1.33 \mathrm{mmol} / \mathrm{g}$. It can be calculated, assuming the radius of a hydrated $\mathrm{Cd}$ (II) ion to be $0.426 \mathrm{~nm}$, that $1.33 \mathrm{mmol} / \mathrm{g}$ of Cd(II) would cover $456.5 \mathrm{~m}^{2} / \mathrm{g}$ for SA-S-C. This value is nearer to the total available surface area (as determined from BET/nitrogen adsorption experiments) of $500.5 \mathrm{~m}^{2} / \mathrm{g}$. It is known that carbon is almost entirely composed of mesopores with pore volumes greater than $7.5 \mathrm{~nm}$. Thus, the adsorption of $\mathrm{Cd}(\mathrm{II})$ would account for the occupation of the entire activated carbon surface including meso- and macropores.

\section{Comparison with other adsorbents}

In order to justify the validity of sulphurised activated carbon as an adsorbent for $\mathrm{Cd}(\mathrm{II})$ adsorption, its adsorption potential must be compared with other adsorbents used for this purpose. The values of $\mathrm{Q}^{\circ}$ and $\mathrm{b}$ for the adsorption of $\mathrm{Cd}(\mathrm{II})$ on different adsorbents 
reported in the literature compared with the adsorbent of the present study are summarised in Table 5. It may be observed that the uptake of $\mathrm{Cd}(\mathrm{II})$ on sulphurised activated carbon is very much greater than other adsorbent materials reported in the literature. However, it is clear from Table 5 that sphagnum moss peat shows much greater (1.33 times) adsorption potential. The high adsorption capacity for this material is probably related to the sorption mechanism including both ion exchange and complexation.

An adsorption isotherm study was also conducted to determine the adsorption capacity of a commercial activated carbon (CAC). For this, a CAC, E.Merck carbon, supplied by E.Merck India Ltd was used. Equilibrium isotherm data at a controlled $\mathrm{pH}$ of 6.0 and a temperature of $30^{\circ} \mathrm{C}$ were correlated using the Langmuir isotherm model. The maximum adsorption capacity, $\mathrm{Q}^{\circ}$ and binding constant, b ofCAC were calculated from the Langmuir plot (Fig. 7) and were $130.21 \mathrm{mg} / \mathrm{g}$ and $0.12 \mathrm{dm}^{3} / \mathrm{mg}$, respectively; which are considerably lower than those of the newly developed activated carbon.

\section{Desorption and regeneration}

Desorption studies assist in the recycling of the adsorbent and recovery of metal. For this purpose, different reagents as extractants were tested. The results of the experiments are shown in Fig. 8. The relatively inexpensive $\mathrm{HCl}$ eluted almost all the bound $\mathrm{Cd}$ (II) from carbon. In contrast $\mathrm{NaNO}_{3}, \mathrm{NaCl}, \mathrm{Na}_{2} \mathrm{SO}_{4}, \mathrm{HNO}_{3}, \mathrm{H}_{2} \mathrm{SO}_{4}$ and $\mathrm{NaCl}+\mathrm{HCl}$ were not efficient in the desorption of Cd(II) ions. An efficiency of $94.4 \%$ was obtained by using $0.2 \mathrm{M} \mathrm{HCl}$ solution and is therefore suitable for the extraction of $\mathrm{Cd}$ (II) into the aqueous phase. Regeneration studies were also carried out for three cycles. Table 6 summarises the results of desorption and regeneration of activated carbon for $\mathrm{Cd}(\mathrm{II})$. After two cycles, the adsorption capacity of activated carbon was reduced by $9.4 \%$ and on the other hand recovery of $\mathrm{Cd}(\mathrm{II})$ ions in $0.2 \mathrm{M} \mathrm{HCl}$ was decreased from $94.4 \%$ in the first cycle to $86.8 \%$ in the third cycle. The small portion of adsorbed $\mathrm{Cd}$ (II) not recoverable by regeneration presumably represents the metal ions which are bound through stronger interactions and, as a result, the sorption efficiency is reduced in subsequent cycles.

\section{Conclusions}

The study indicated that sulphurised steam activated carbon prepared from sugar cane bagasse pith could be used as an effective adsorbent material for the treatment of Cd-bearing aqueous waste streams. The adsorption of $\mathrm{Cd}(\mathrm{II})$ onto activated carbon is found to be time, concentration, $\mathrm{pH}$ and temperature dependent. The maximum percentage removal occurs between the $\mathrm{pH}$ range of 5.0 to 9.0. Adsorption data indicate the applicability of pseudo-secondorder kinetics. The removal of Cd(II) by this activated carbon is an endothermic process. The calculated $\mathrm{E}_{\mathrm{a}}$ for the adsorption is 18.28 $\mathrm{kJ} / \mathrm{mol}$, indicating that the adsorption has a low potential energy barrier. The isotherm study indicates that sorption data can be adequately modelled by the Langmuir adsorption isotherm. Spent adsorbent can be regenerated using $0.2 \mathrm{M} \mathrm{HCl}$.

\section{Acknowledgements}

The authors are thankful to the Professor and Head, Department of Chemistry, University of Kerala, Trivandrum for providing laboratory facilities. One of the authors (KA Krishnan) is grateful to the Council of Scientific and Industrial Research, Government of India, New Delhi, for the financial support in the form of Senior Research Fellow.

\section{References}

ALLEN S, BROWN F, MCKAY G and FLYNN O (1992) An evaluation of single resistance transfer model in the sorption of metal ions by peat. J. Chem. Tech. Biotechnol. 54 271-276.

BENJAMIN MM and LECKIE JO (1982) Effects of complexation by $\mathrm{Cl}$, $\mathrm{SO}_{4}$ and $\mathrm{S}_{2} \mathrm{O}_{3}$ on the adsorption behaviour of $\mathrm{Cd}$ on oxide surfaces. Environ. Sci. Technol. 16 162-170.

BOEHM HP and VOLL M (1970) Basic surface oxides on carbon: I Adsorption of acids. Carbon 8 (2) 227-240.

BUDINOVA TK, GERGOVA KM, PETROV NV and MINKOVA VN (1994) Removal of metal ions from aqueous solutions by activated carbons obtained from different raw materials. J. Chem. Tech. Biotechnol. 60 177-182.

CHEREMISINOFF PN (1995) Handbook of Water and Wastewater Treatment Technology. Marcel Dekker Inc, New York.

DASNC and BANDYOPADYAYM(1991) Removal of lead by vermiculate medium. Appl. Clay Sci. 6 221-231.

DRASH GA (1993) Increase of cadmium body burden for this century. Sci. Total Environ. 67 75-89.

GOMEZ-SERRANO V, MACIAS-GARCIA A, ESPINOSA-MANSILLA A and VALENZUELA-CALAHORRO C (1998) Adsorption of mercury, cadmium and lead from aqueous solution on heat-treated and sulphurised activated carbon. Water Res. 32 1-4.

GUPTA VK, MOHAN D and SHARMA S (1998) Removal of lead from wastewater using bagasse fly ash - A sugar industry waste material. Sep. Sci. Technol. 33 1331-1343.

HALLUM JV and DRUSHELL HV (1958) The organic nature of carbon surfaces. J. Phys. Chem. 62 110-117.

HO YS, JOHN WASE and FORSTER CF (1995) Batch nickel removal from aqueous solution by sphagnum moss peat. Water Res. 29 13271332.

HO YS and MCKAY GS (2000) The kinetics of sorption of divalent metal ions onto sphagnum moss peat. Water Res. 24 735-741.

HO YS, NG JCY and McKAY G (2001) Removal of lead(II) from effluents by sorption on peat using second-order kinetics. Sep. Sci. Technol. 36 241-261.

JAMES R and PARKS GA (1982) Surface and Colloid Science. (Ed. DT Matpec), Plenum Press, New York.

JOHNSON BB (1990) Effect of pH, temperature and concentration on the adsorption of cadmium on goethite. Environ. Sci. Technol. $24112-$ 118.

LARSON VJ and SCHIERUP HH (1981) The use of straw for removal of metals from wastewater. J. Environ. Qual. 10 188-193.

MANJU GN and ANIRUDHAN TS (1997) Use of coconut fibre pith-based pseudo-activated carbon for chromium(VI) removal. Indian J. Environ. Health 4 289-298.

MANJU GN, RAJI C and ANIRUDHAN TS (1998) Evaluation of coconut husk carbon for the removal of arsenic from water. Water Res. 32 3062-3070.

McKAY G, BLAIR HS and FINTON A (1986) Sorption of metal ions by chitosin. In: Eccles $\mathrm{H}$ and Hunt $\mathrm{S}$ (eds.) Immobilisation of Ions by Biosorption, Ellis Harwood, Chichester UK. 59-69.

NAKANISHI K and SOLAMON PH (1977) Infrared Absorption Spectroscopy. Holden Day, Inc, USA.

NAMASIVAYAM C and RANGANATHAN K (1995) Removal of Cd(II) from wastewater by adsorption on "waste" Fe(III)/Cr(III) hydroxide. Water Res. 29 1737-1744.

OKIEIMAN FE, OKUNDIA EV and OGBEIFUN DE (1991) Sorption of cadmium and lead ions on modified groundnut (Arachis hypogea) husks. J. Chem. Tech. Biotechnol. 51 97-103.

OSIPOW LI (1972) Surface Chemistry: Theory and Industrial Applications. Krieger, New York.

PEARSON RG (1988) Absolute electronegativity and hardness: Application. Inorg. Chem. 27 734-738.

PETERNELE WS, WINKLER-HECHENLEITNER AA and GOMEZ PINEDA EA (1999) Adsorption of Cd(II) and Pb(II) onto functionalized formic lignin from sugar cane bagasse. Bioresour. Technol. 68 95-100.

PRADAS EG, SANCHEZ MV, CRUZ FC, VICIANA MS and PEREZ MF (1994) Adsorption of cadmium and zinc from aqueous solution on 
natural and activated bentonite. J. Chem. Tech. Biotechnol. 59 289-295.

RAJI C and ANIRUDHAN TS (1997) Chromium (VI) adsorption by sawdust carbon: Kinetics and equilibrium. Indian J. Chem. Technol. 4 228-236.

RAJI C and ANIRUDHAN TS (1999) Sorption characteristics of As(III) on surface modified sawdust carbon. Indian J. Environ. Health 41 184193.

RAJI C, MANJU GN and ANIRUDHAN TS (1997) Removal of heavy metal ions from water using sawdust-based activated carbon. Indian J. Eng. Mater. Sci. 4 254-260.

RAMOS RL, MENDEZ JRR, BARRON JM, RUBIO LF and CORONADO RMG (1997) Adsorption of Cd(II) from aqueous solutions onto activated carbon. Water Sci. Technol. 35 205-211.

RUMP HH and KRIST H (1992) Laboratory Manual for the Examination of Water, Wastewater and Soil. VCH, New York.

SCHAWRZ JA, DRISCOLL CT and BHANOT AK (1984) The zero point charge of silica-alumina oxide suspensions. J. Colloid Interface Sci. 97 55-61.
SINGH D and RAWAT NS (1994) Bituminous coal for the treatment of Cd(II) rich water. Indian J. Chem. Technol. 1 266-270.

SREEDHAR MK, MADHUKUMAR A and ANIRUDHAN TS (1999) Evaluation of an adsorbent prepared by treating coconut husk with polysulphide for the removal of mercury from wastewater. Indian $J$. Eng. Mater. Sci. 6 279-285.

SRINIVASA RAO M and BANDYOPADYAY M (1995) Cadmium pollution control by kimberlite tailings. J. Indian Assoc. Environ Manage. 22 124-129.

VILADKAR S, AGARWAL R and KAMALUDIN A (1996) Adsorption of adenine, adenosine and adenosine nucleotides on nickel(II)hexacyanoferrate(II). Bull. Chem. Soc. Jpn. 69 95-100.

WARHURST AM, MCCONNACHIE GL and POLLARD SJT (1997) Characterization and applications of activated carbon produced from Moringa oleifera seed husk by single-step steam pyrolysis. Water Res. 31 759-766. 